\title{
Numerical Simulation of a Full Scaled Fire Test of the Tunnel with Natural Ventilation
}

\author{
Mehdi Rafiei \\ Institute of Internal Combustion Engines and Thermodynamics \\ Graz University of Technology, \\ Austria, 8010 Graz, Inffeldgasse 21/A
}

\begin{abstract}
A mechanical ventilation system plays a major role in tunnels safety. Over the world, different ventilation systems regarding to the tunnel geometry and other parameters are used for tunnel ventilation in the normal and fire operations. However, in short tunnels depending on the tunnel geometry and traffic condition, there is the possibility of passing traffic through a tunnel without mechanical ventilation. Normally, natural ventilation is applied in short tunnels. In longer tunnels, additional measures in geometry such as openings or shafts are necessary to support natural ventilation. Due to the high costs of the electro-mechanical installations, maintenance and electricity power consumption for mechanical ventilation, having tunnels with natural ventilation system will be the best option. But, reliability of such ventilation systems in case of emergency must be substantiated before applying to tunnels. The main concern is a proper smoke evacuation in a fire case. In this survey, in order to set up a suitable CFD model, numerical simulation of a pre-conducted fire test by using same boundary conditions is done. These simulations were further extended to fires with higher capacities to show smoke and temperature behavior during the higher fires. The newest version of the FDS software (Fire Dynamic Simulator 6) was employed for simulations.
\end{abstract}

\section{Keywords}

Natural ventilation, Tunnel fire, Fire simulation, Smoke propagation, FDS 6

\section{INTRODUCTION}

Ventilation purpose is different in normal and fire cases, though both are for user's safety in tunnels. Management and evacuation of the hot and toxic gases during the fires and dilution of the released emissions or aerosols by the cars in normal operation are the main targets for the tunnel ventilation system. Ventilation control in tunnels with natural ventilation systems, especially during a fire is not possible. Any air movement is influenced by meteorological or environmental conditions during the fire. Openings in the ceiling or shafts instead of mechanical ventilation are considered in order to perform ventilation in fire and normal cases [1-3]. Such kind of natural ventilation systems are practicable in tunnels with low covering and could be a suitable solution for long underpasses built in cut and cover. Dimension and location of the openings are very important in order to cope with all probable fire scenarios in different locations with various heat release rates (HRR).
In order to check proper system operation in the tunnels, usually fire and hot smoke tests are performed during commissioning phase. In tunnels with a mechanical ventilation system, fire tests with a limited HRR are performed [1, 2, and 7]. In tunnels with natural ventilation, control of the fire or emergency situation is not possible. The result of a low capacity fire test cannot prove the safety of the tunnel during high capacity fires. For this reason numerical simulation of fires with different capacities could be beneficial. An experimental investigation has been done for the smoke and temperature behavior during the fire in the tunnel with natural ventilation system $[1,2]$. In this full-scaled fire test with a capacity of $5.4 \mathrm{MW}$, the operation of the existing openings and shafts was investigated. The experimental data showed good performance of the shafts for venting hot smoke and toxic gases. Referring to the traffic condition, most of the passing traffic through the tunnel is passenger cars. Hence according to the tunnel safety guidelines, a heat release rate of $5.4 \mathrm{MW}$ is sufficient for acceptable tunnel safety. This paper will concentrate on CFD simulation of fire in the tunnel with natural ventilation using experimental data. The software tool FDS will be employed for numerical simulation. After proving the applicability of the computer model set up for 5.4 MW case, simulations will be performed for a higher capacity fire scenario $(30 \mathrm{MW})$.

\section{TUNNEL GEOMETRY AND TRAFFIC PARAMETERS}

Geometry of the tunnel, traffic condition and all other referenced parameters for model set-up and calculations were taken from the conducted fire test [1]. The length of the twin bore tunnel with three lanes was about $1410 \mathrm{~m}$. Each tunnel has a rectangular cross section of 12.35 width and $5.75 \mathrm{~m}$ height in both tubes and five shafts in series for natural ventilation with length, width and height of 109, 2.6 and $6 \mathrm{~m}$, respectively. All of the five shafts are divided into four equal sections $(2.6 \times 3 \times 6)$ using middle walls. Both of the tunnels are using the shafts for ventilation with in shared condition. Longitudinal slope which can affect the natural ventilation, especially during a fire [4], was negligible in the fire test location. For this reason longitudinal slope is not considered in the simulations. The unidirectional operated tunnel is mainly used by passenger cars. Figure 1 and Figure 2 show more details from the mentioned tunnel geometry and FDS model. 


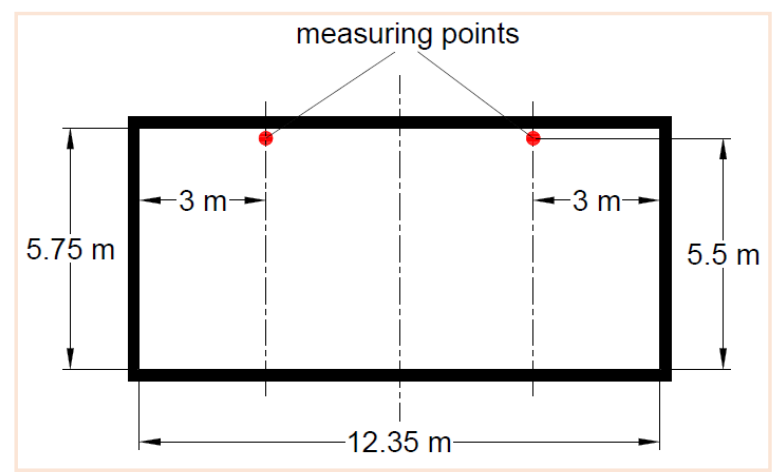

Fig 1: Tunnel cross section with measuring points [1]

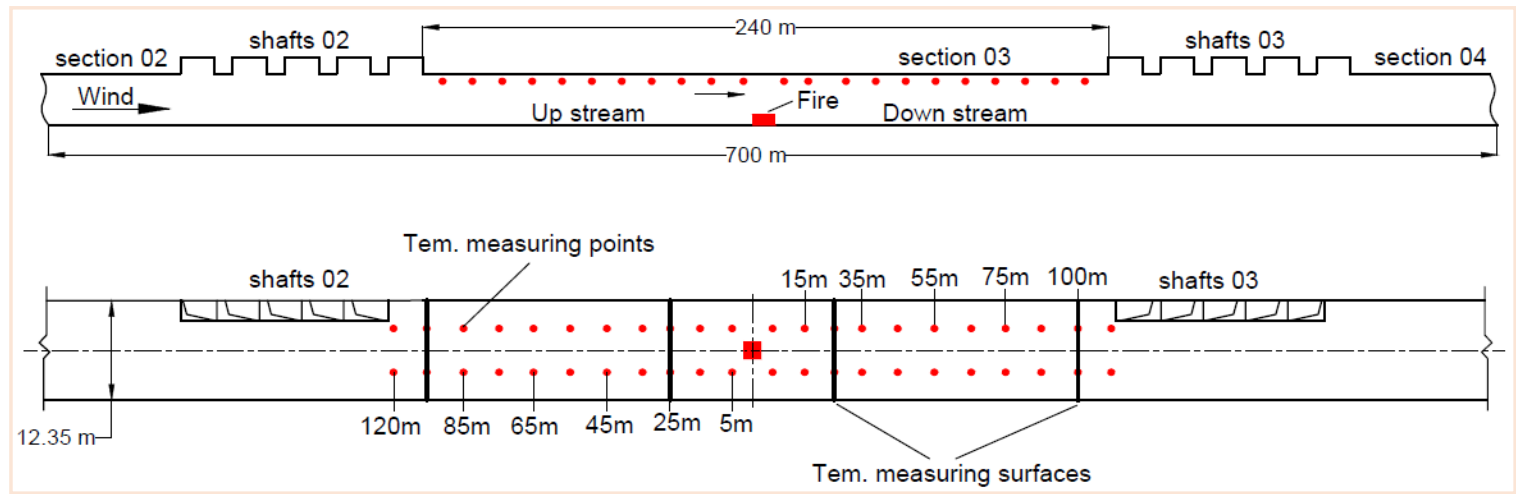

Fig 2: Tunnel plan with measuring point and surfaces [1]

The fire was located in the middle of the third section. The computational domain, from the beginning of the second section to end of the fourth section, was roughly $700 \mathrm{~m}$. Simulation results indicated a proper evacuation of smoke through the shafts in the selected computing domain and the smoke hasn't spread to the out of computing domain. Thus, a length of $700 \mathrm{~m}$ from the whole tunnel was sufficient for the calculations and effectively helped to reduce the computation time.

\section{EXPERIMENTAL STUDIES BASIC INFORMATION}

\subsection{Fire scenario analysis}

Three fire scenarios were done in the tunnel to check the performance of the shafts during the fire tests. The second scenario was proposed to be the most critical scenario due to distances between the fire and related evacuation shafts. This has been confirmed, by the experimental tests, due to long distance for smoke transport. Hence the second fire test selected for simulation studies. A mixture of diesel fuel and gasoline was used as fire source in the conducted fire test. The fuel (92\% diesel and $8 \%$ gasoline) has been poured into the pool $(1.8 \times 1.8 \times 0.05 \mathrm{~m})$ to burn. This resulted in a maximum HRR of 5.4 MW [1].

\subsection{Environmental boundary condition}

An ambient temperature of $5{ }^{\circ} \mathrm{C}$ and natural wind speed of $0.8-1.5 \mathrm{~m} / \mathrm{s}$ has been recorded at the central axis of the tunnel [1]. These values were applied as boundary conditions in CFD model.

\section{CFD MODELING}

\subsection{Fire dynamic simulator}

Fire dynamics simulator (FDS) is used for numerical simulation of the selected fire scenarios in this study. FDS solves specific forms of the Navier-Stokes equations for low airflows $(\mathrm{Ma}<0.3)$ resulting from the fire and solves combustion and energy equations to simulate burning, smoke and heat transfer $[5,6]$.

\subsection{Fire boundary condition}

Figure 3 shows the HRR for the 5.4 MW fire case over the simulation time. The profile has been calculated regarding to the involved surface of the fuel pool in the burning process during the fire test. The obtained curve for HRR was used as fire boundary condition for the numerical simulations. A delay of 400 seconds for the start of the fire was considered to allow sufficient time for airflow to reach steady state conditions in the tunnel. The maximum HRR was achieved within 240 seconds after the beginning of the fire and remained constant till to the end of the simulation. 


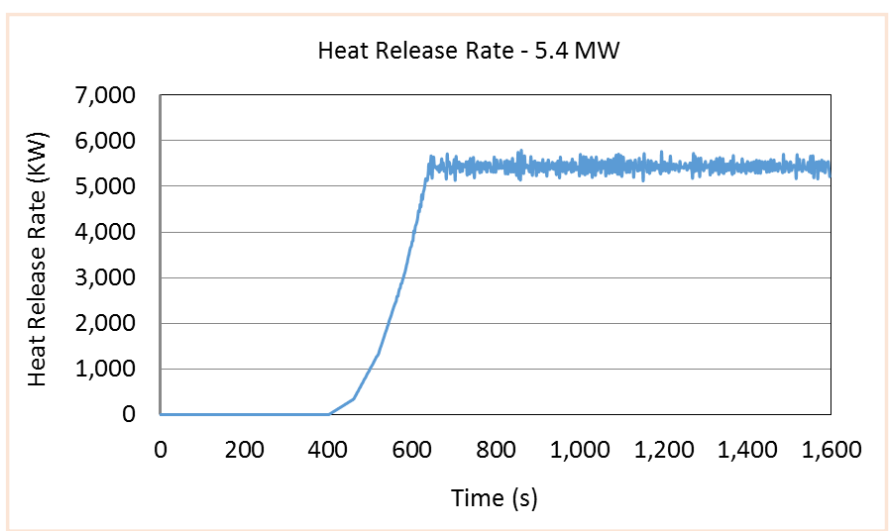

Fig 3: Heat release rate, fire simulation 5.4MW

\subsection{Air velocity boundary condition}

Many experimental and CFD studies, over the world, have been conducted in order to evaluate the impact of the airflow on temperature and smoke distributions during the fire in tunnels [7-13]. The results have proven the direct influence of the airflow on smoke and temperature behavior. In tunnels with natural ventilation system, ambient wind also will have an effect on temperature and smoke behavior during a fire. Natural wind speed was recorded $0.8-1.5 \mathrm{~m} / \mathrm{s}$ at the center line of the tunnel during the fire test. This range of values was considered to create an airflow boundary for the CFD models. A higher natural air flow can prevent a proper smoke evacuation through the one or even both shafts. For this reason, roughly, the highest longitudinal air velocity reported during the fire test, was applied as a boundary condition. Figure 4 shows average U-velocity boundary, calculated by CFD model, in the tunnel cross section at the location of 100 $\mathrm{m}$ after entrance portal. According to the curve average longitudinal airflow is about $1.45 \mathrm{~m} / \mathrm{s}$. The steady-state situation for airflow, which is an effective parameter in the simulation results, was reached of around 400 seconds and before the beginning of the fire. This boundary condition was employed to $30 \mathrm{MW}$ fire simulations as well.

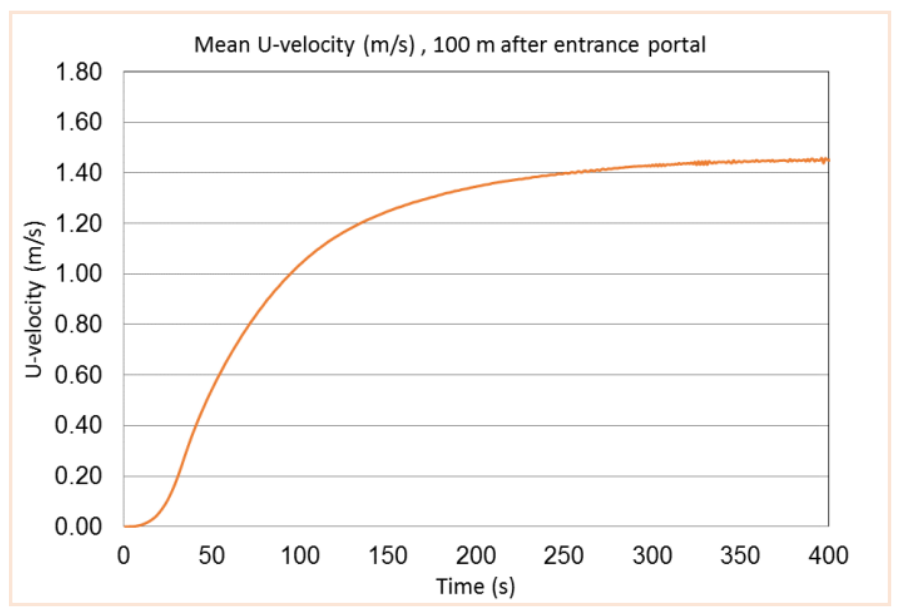

Fig 4: Average $\mathrm{U}$-velocity $100 \mathrm{~m}$ downstream the entrance portal

\section{SIMULATION RESULTS}

\subsection{Simulation results for $5.4 \mathrm{MW}$ fire}

Figure 5 indicates the temperature and smoke distributions in the vertical symmetry plane of the tunnel for a $5.4 \mathrm{MW}$ fire case. About 500 seconds after the start of the calculation, or 100 seconds after the beginning of fire, smoke was propagated roughly $60 \mathrm{~m}$ in the upstream and $20 \mathrm{~m}$ in the downstream. These values increased to about 180 and 80 when HRR reached to the maximum (640 s) value, respectively. At this time, smoke came down to about $2 \mathrm{~m}$ above roof surface. After 1000 seconds, the propagation of the smoke in the upstream was about $260 \mathrm{~m}$ whereas downstream was around $130 \mathrm{~m}$. The notable difference in the smoke development is due to the effect of natural wind. Over the time, the development of smoke is limited due to the evacuation of smoke by the shafts. The overall developed length of the smoke, after balancing between production and evacuation was approximately 140 and $220 \mathrm{~m}$ down - and upstream, respectively. Smoke back-layering in the downstream was about $60 \mathrm{~m}$ less than experimental data. This could be due to the assumed air velocity for simulation, which was close to the highest value. The distribution of the temperature in the symmetry plane of the tunnel depends on the concentration of hot smoke or gases. The temperature at the top level (up to about $3 \mathrm{~m}$ under the ceiling) of the symmetry plane was calculated between 20 to $105{ }^{\circ} \mathrm{C}$ depending on the distance of locations from fire and distances from ground level. In the low levels the temperature was less than $15^{\circ} \mathrm{C}$. 


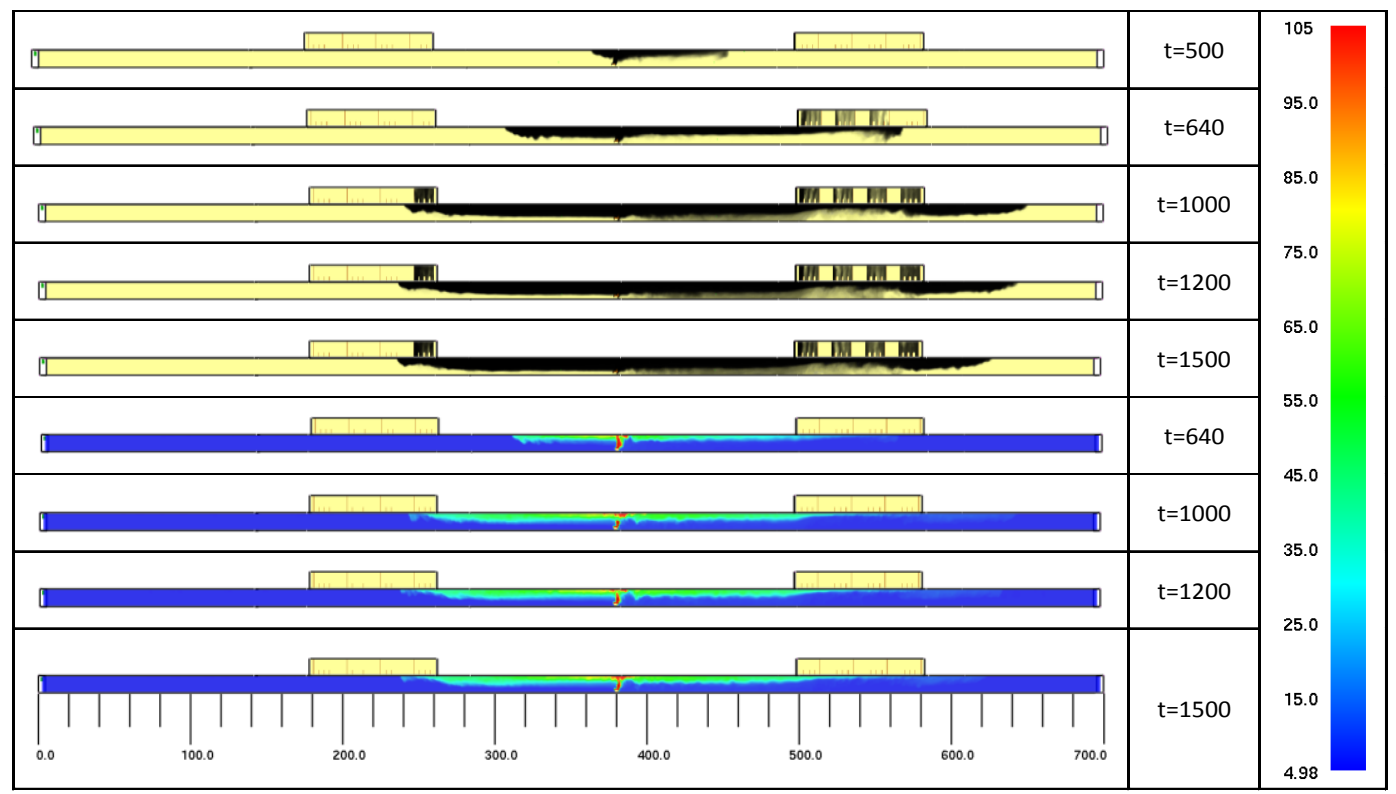

Fig 5: Smoke propagation and temperature $\left({ }^{\circ} \mathrm{C}\right)$ distribution over the simulation time (s) - 5.4 MW

Figure 6 shows other details from the temperature variations in the different surfaces of tunnel cross section. The measurement surfaces were located at the position of 25 and $100 \mathrm{~m}$ before (left) and after (right) the fire. In these places, the maximum temperature was found close to the ceiling of around $75{ }^{\circ} \mathrm{C}$. According to the results, the range of the temperature close to the floor up to an elevation of about $2 \mathrm{~m}$ was not exceed $20{ }^{\circ} \mathrm{C}$ during the whole simulation time. This can create an opportunity for rescue and firefighting in the low fire capacities. However, the risk of the poisoning by toxic gases after a few minutes from the beginning of the fire is the main concern. Along with the directing people to out of the fire and smoke area, injured peoples must be transferred immediately to the safer locations.

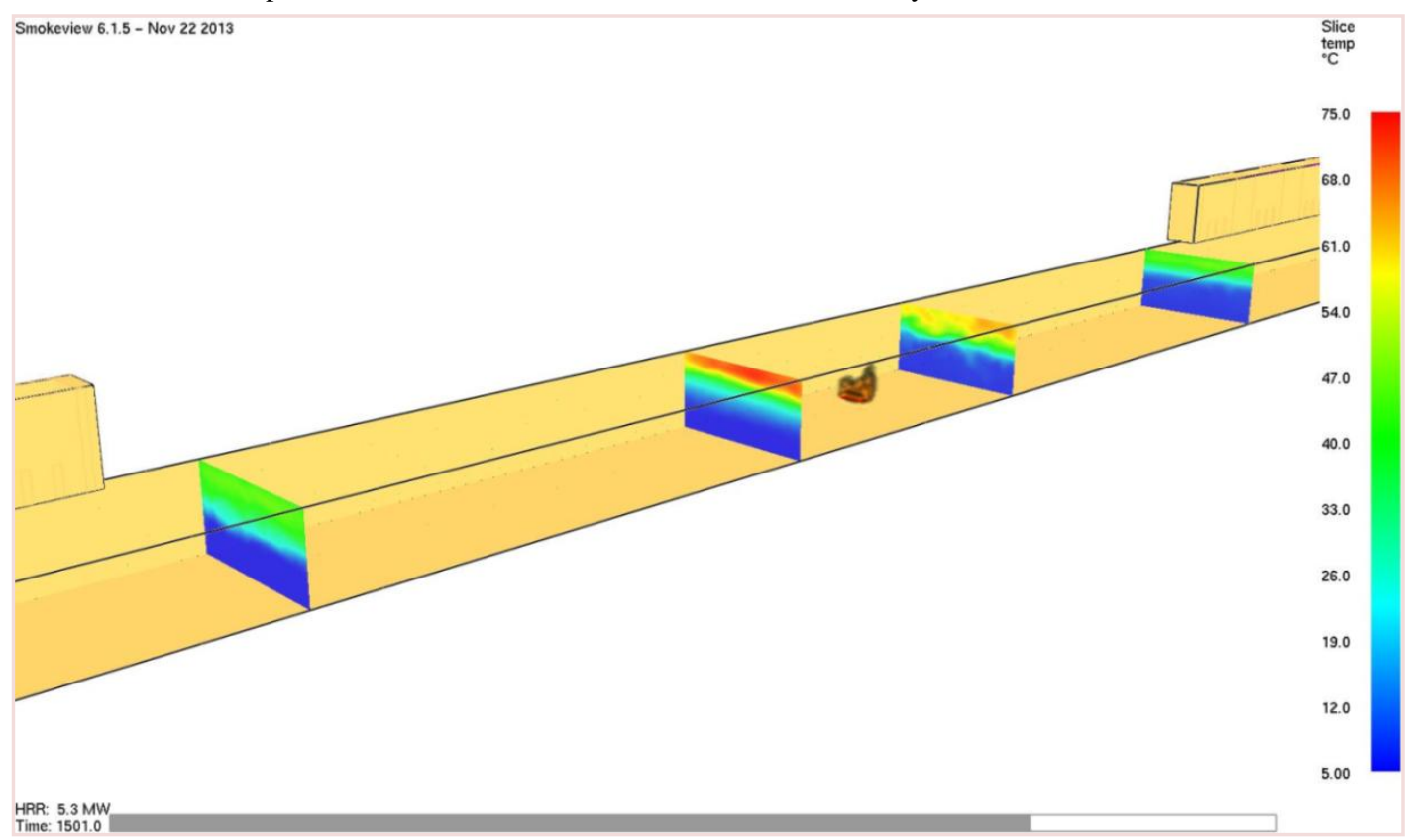

Fig 6: Temperature $\left({ }^{\circ} \mathrm{C}\right)$ in the cross section, 100 and $25 \mathrm{~m}$ before and behind fire $(1500 \mathrm{~s})-5.4 \mathrm{MW}$

Figure 7 shows the average temperature at the points located downstream with an interval of 5 to $120 \mathrm{~m}$ from the fire and at the height of $5.5 \mathrm{~m}$ above the ground level. These locations were chosen with respect to the reference points used in the fire test. Figure 8 depicts the same information at the same distance upstream. The maximum and minimum observed temperatures are $80,40{ }^{\circ} \mathrm{C}$ downstream and $87,35{ }^{\circ} \mathrm{C}$ upstream, respectively. The upstream temperature at top level was slightly higher compared to downstream, which might result from blocking hot smoke between shaft and fire by natural airflow. At lower levels this happens exactly in the opposite due to cold airflow toward the fire from downstream. 


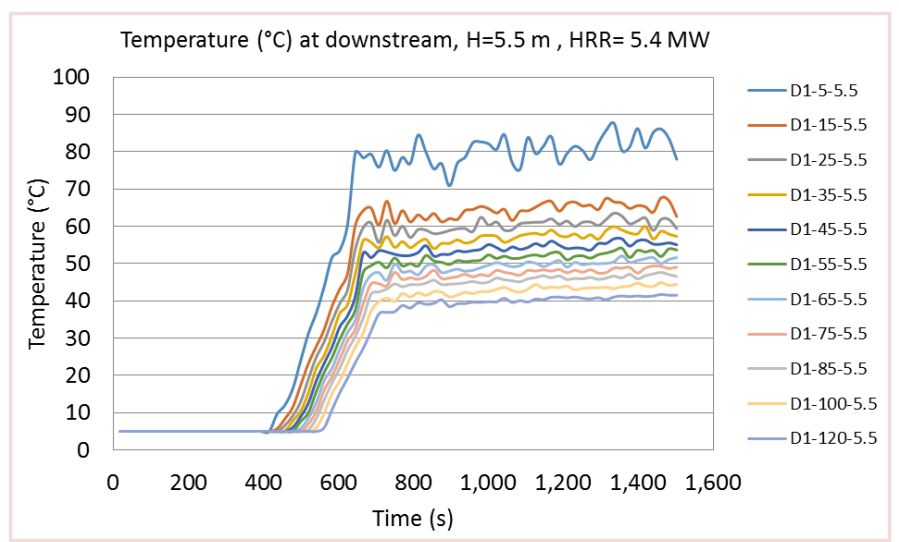

Fig 7: Temperature $\left({ }^{\circ} \mathrm{C}\right)$ behavior at the downstream of the fire $-5.4 \mathrm{MW}$

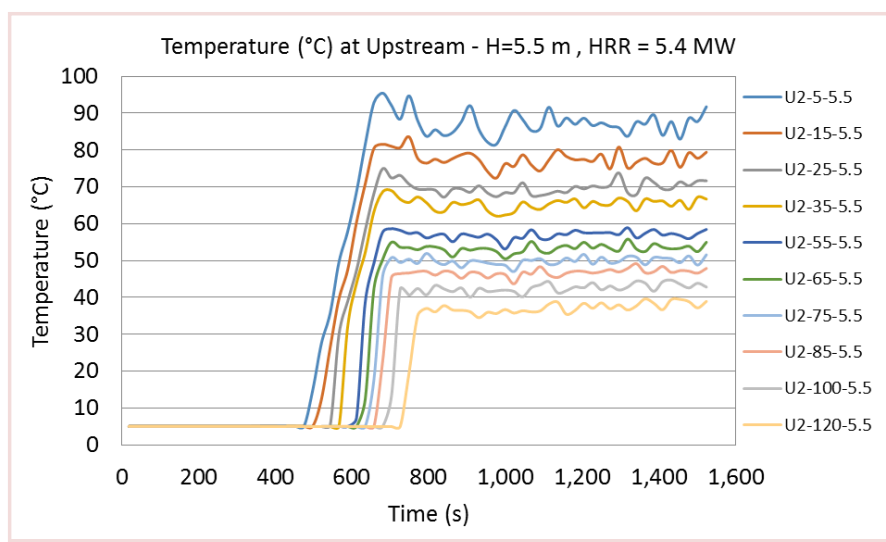

Fig 8: Temperature behavior at the upstream of the fire $-5.4 \mathrm{MW}$

Figure 9 indicates the longitudinal air velocity (U-velocity) at the symmetry plane of the tunnel, obtained from the numerical simulation of the 5.4 MW fire case. The upstream air velocity, over the simulation time, has increased from boundary level at the beginning ( $400 \mathrm{~s}$ ) to about $2 \mathrm{~m} / \mathrm{s}$ during the maximum rate of the heat release (640 s and later). The back layering results in negative air/smoke movement at the ceiling and increased air flow of ground level. The average velocity of the relatively steady airflow at the downstream has reached about $1 \mathrm{~m} / \mathrm{s}$.

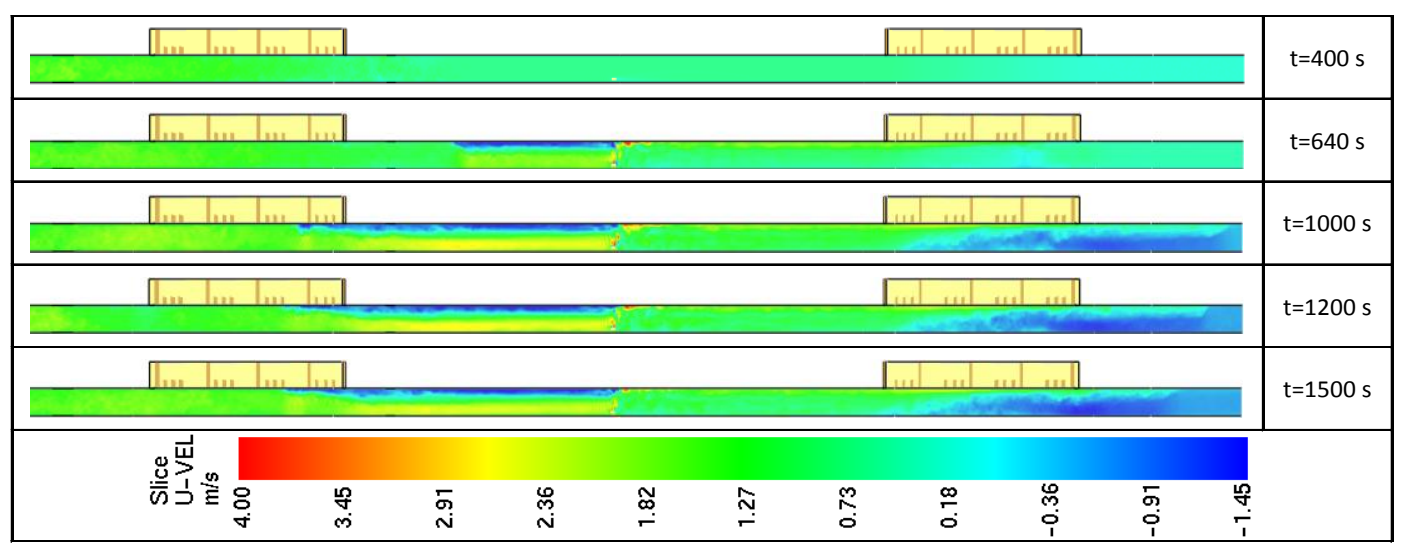

Fig 9: U-velocity $(\mathrm{m} / \mathrm{s})$, at the vertical surface in the middle of the tunnel $-5.4 \mathrm{MW}$

\subsection{Simulation results for $30 \mathrm{MW}$ fire}

Figure 10 depicts the distribution of smoke and temperature for a $30 \mathrm{MW}$ fire case. Comparing to the $5.4 \mathrm{MW}$ fire case, the maximum temperature was calculated approximately 5 times higher. The smoke developed faster along the longitudinal and vertical axis. Due to the high temperature and therefore higher air velocity, higher airflow turbulence observed when the maximum HRR achieved and later. This leads to more turbulent diffusion of smoke to lower levels. On the other hand, extraction of the smoke and preventing it from the spreading to other sections indicates proper functioning of the shafts during a $30 \mathrm{MW}$ fire case. 


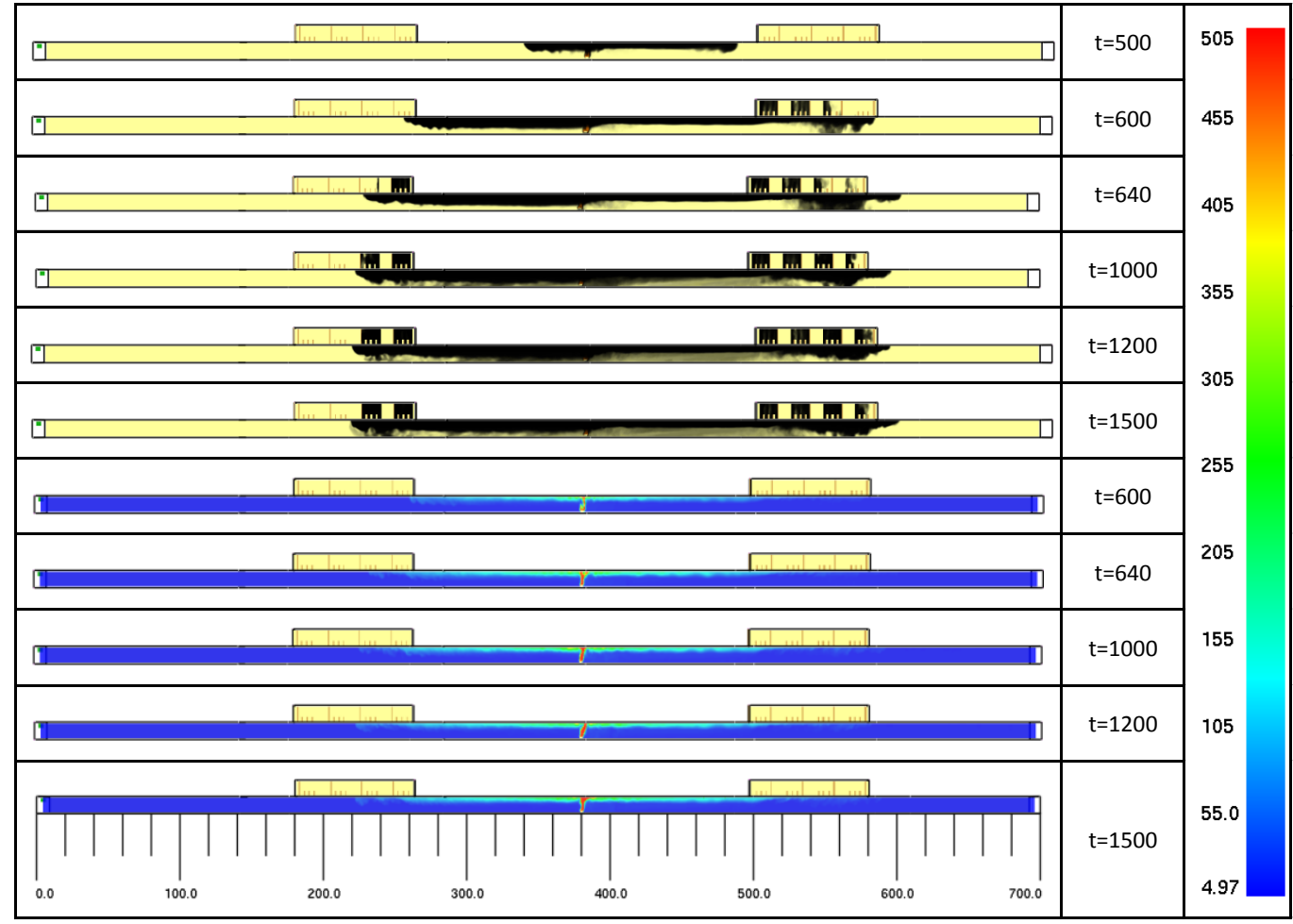

Fig 10: Smoke propagation and temperature $\left({ }^{\circ} \mathrm{C}\right)$ distribution over the simulation time $(\mathrm{s})-30 \mathrm{MW}$

Figure 11 depicts the cross sectional temperature variations, at a distance of 100 and $25 \mathrm{~m}$ from the fire on the both sides. Temperature values depending on the location and simulation times were calculated between $100{ }^{\circ} \mathrm{C}$ to $255^{\circ} \mathrm{C}$ at the ceiling. At the same, the temperature at the ground level didn't exceed
$30{ }^{\circ} \mathrm{C}$. In this case, according to the obtained higher range of the temperature and smoke diffusion, the risks are quite high. All people must be transferred to the safer locations before the maximum capacity of fire achieved.

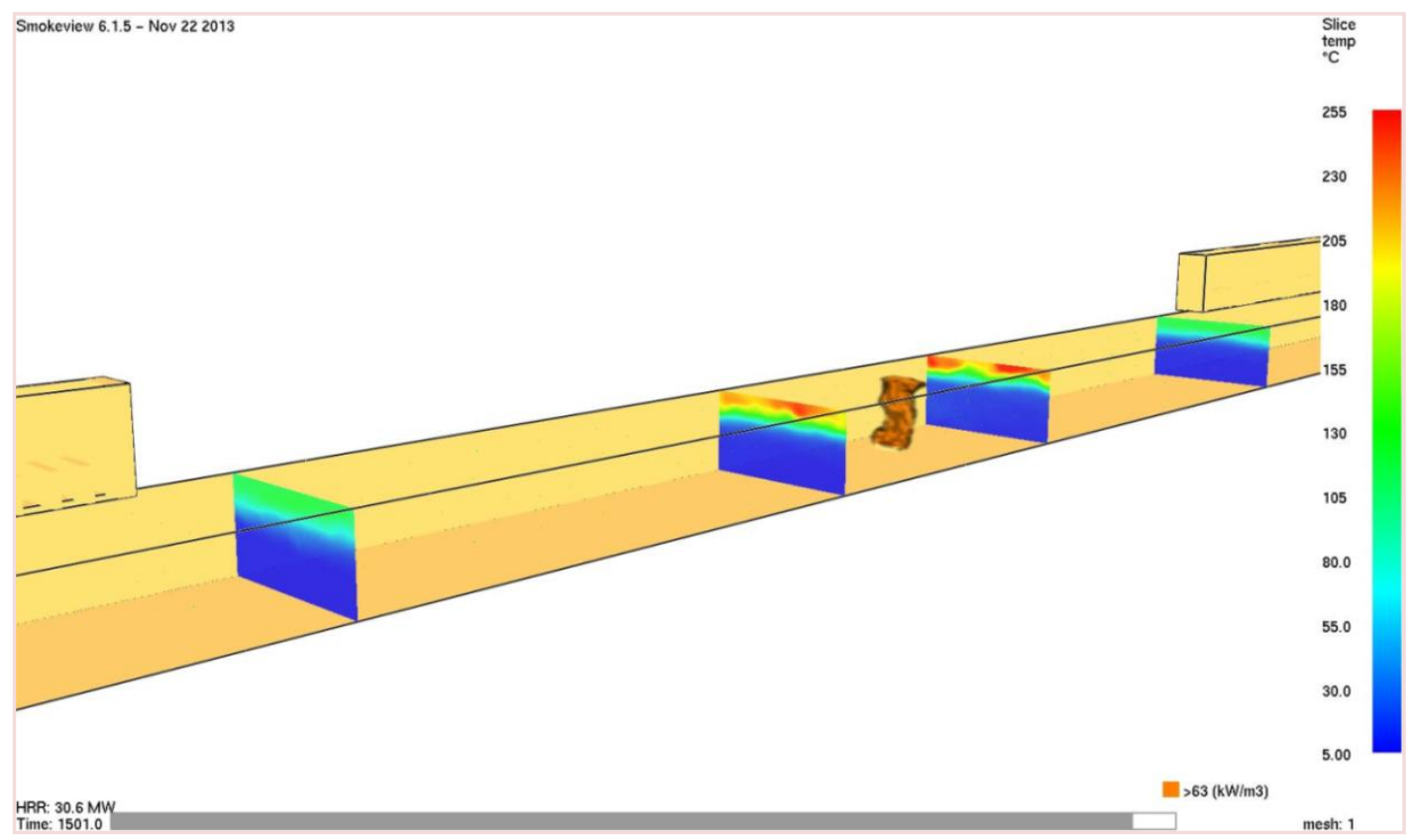

Fig11: Temperature $\left({ }^{\circ} \mathrm{C}\right)$ in the cross section, 100 and $25 \mathrm{~m}$ before and behind fire $(1500 \mathrm{~s})-30 \mathrm{MW}$

Figure 12 and Figure 13 show the average temperature of the points located at the same position as discussed in the 5.4 MW case. The maximum temperature at downstream is observed of roughly $400{ }^{\circ} \mathrm{C}$ for a $30 \mathrm{MW}$ fire. Maximum temperature at the upstream amounted to around $325{ }^{\circ} \mathrm{C}$. Minimum temperatures in the up-and downstream were observed about $100,110^{\circ} \mathrm{C}$, respectively. Contrary to the $5.4 \mathrm{MW}$ simulation, applying the same natural air flow conditions, the temperature in the upper regions of the cross section are higher downstream than upstream. This might be due to the higher buoyancy effects. 


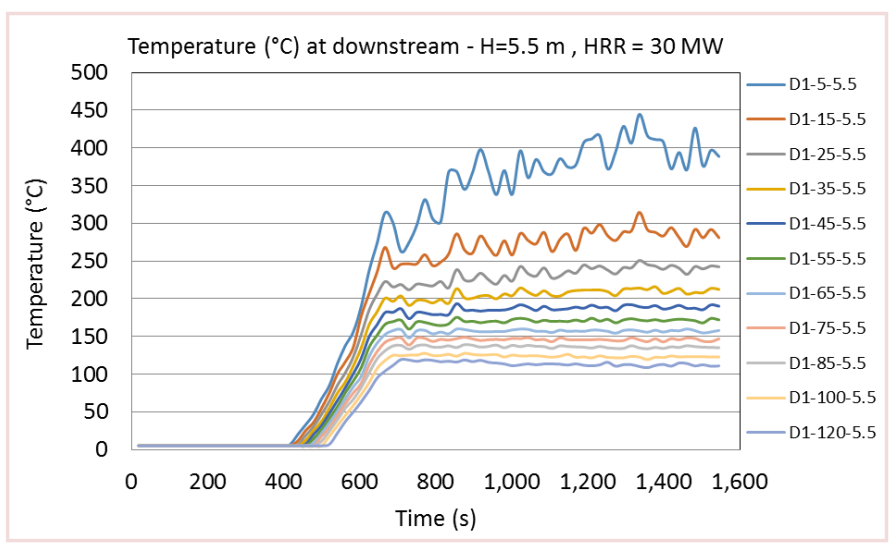

Fig 12: Temperature behavior downstream of the fire - 30MW

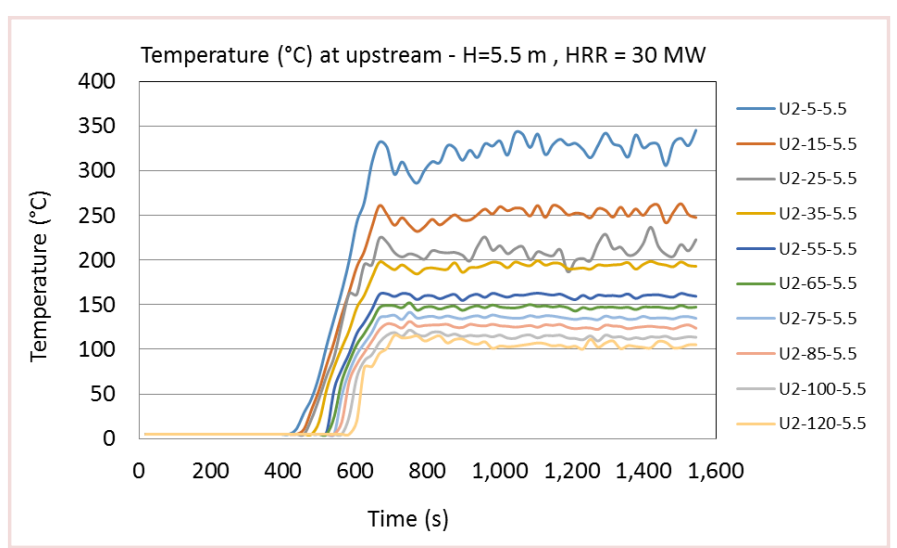

Fig 13: Temperature behavior upstream of the fire - 30MW

Figure 14 depicts the air velocity variations (U-velocity) in the symmetry plane of the tunnel cross section of different time of the simulation for a $30 \mathrm{MW}$ fire. The above mentioned effect of turbulence on smoke distribution was confirmed in the air velocity profiles. The outcomes also are indicating the beginning of a relatively stable situation for the airflow, when calculations reached to the maximum capacity of HRR. The scope of positive air velocity, depending on the elevation was $2-3.2 \mathrm{~m} / \mathrm{s}$ in the upstream. Meanwhile, an average velocity was seen roughly $1 \mathrm{~m} / \mathrm{s}$ in the downstream.

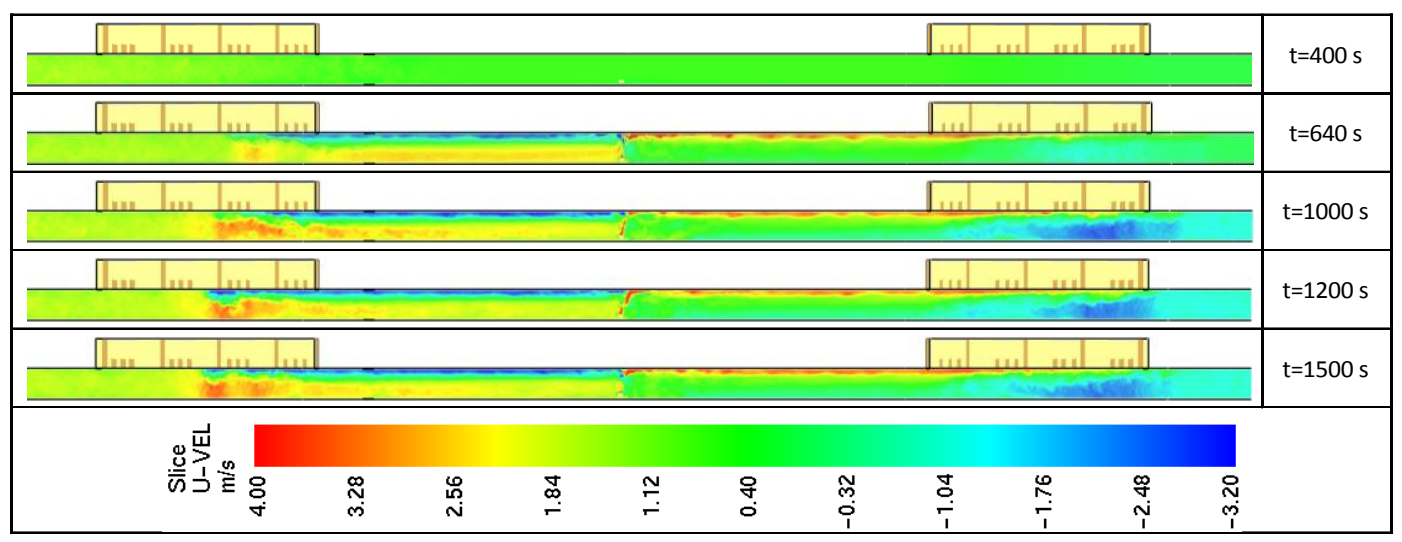

Fig 14: U-velocity $(\mathrm{m} / \mathrm{s})$, at the vertical surface in the middle of the tunnel - $30 \mathrm{MW}$

\section{CONCLUSIONS}

The worst conducted fire scenario was selected for numerical simulation studies. Numerical simulation results were in quite good agreement with recorded data for temperature and smoke behaviors in the $5.4 \mathrm{MW}$ fire test. The results also indicate appropriate smoke extraction by shafts during a fire; hence, the temperature will not have a harmful and devastating impact in this fire case. Nevertheless, there is a possibility of intoxication for users due to the smoke and toxic gases, especially in the downstream after a few minutes from starting the fire.

Simulation results also confirm acceptable extraction of the smoke and appropriate performance of shafts during the 30 MW fire. In this case, the temperature wasn't the main concern during the first few minutes of the fire (before maximum HRR) in the lower level. However, according to the discussed turbulent diffusion to ground level, hot smoke and toxic gases will be threatened for user's life on both sides of the fire after passing the maximum HRR. Appropriate 
reactions dealing with the devastating impacts of the high capacity fires are proper rescue and timely extinguishing operations. However, with respect to the simulation results depending on the used materials for tunnel construction, structural damages around the fire can happen.

\section{ACKNOWLEDGMENTS}

I would like to thank Prof. Sturm for valuable advices and IVT- Institute of Internal Combustion Engines and Thermodynamics (TU Graz) for support of FDS simulations.

\section{REFERENCES}

[1] Tong Yan, Shi MingHeng, Gong YanFeng, He JiaPeng. 2009. Full-scale experimental study on smoke flow in natural ventilation road tunnel fires with shafts. Tunneling and Underground Space Technology, 24, 627633.

[2] Yanfu Wang, Juncheng Jiang, Dezhi Zhu. 2009. Fullscale experiment research and theoretical study for fires in tunnels with roof openings. Fire safety Journal, 44, 339-348.

[3] Yanfu Wang, Juncheng Jiang, Dezhi Zhu. 2009. Diesel oil pool fire characteristic under natural ventilation conditions in tunnels with roof openings. Journal of Hazardous Materials, 166, 469-477.

[4] Liang Yi, Qiqi Xu, Zhisheng Xu, Dexing Wu. 2014. An experimental study on critical velocity in sloping tunnel with longitudinal ventilation under fire. Tunneling and Underground Space Technology, 43, 198-203.

[5] McGrattan, k., Hostikka, S., McDermott, R., Floyd, J., Weinschenk, C., Overholt, K. Fire Dynamics Simulator User's Guide (Version 6.1.1). NIST Special Publication 1019 Sixth Edition; 2014.
[6] Glenn P. Forney. Fire Dynamics Simulator Volume I: User's Guide (Version 6.1.11). NIST Special Publication 1017-1 Sixth Edition; 2014.

[7] Rafiei, M., Sturm, P.J. 2014. Influence of fires on-air velocity measurements at downstream measurement locations. 7th International Conference Tunnel Safety and Ventilation, Graz, Austria, pp. 265-272.

[8] Ying Zhen Li, Bo Lei, Haukur Ingason. 2010. Study of critical velocity and backlayering length in longitudinally ventilated tunnel fires. Fire safety Journal, 45, 361-370.

[9] C.G. Fan, J. Ji, Z.H. Gao, J.Y. Han, J.H. Sun. 2013. Experimental study of air entrainment mode with natural ventilation using shafts in road tunnel fires. International journal heat mass transfer. 56, 750-757.

[10] Jae Seong Roh, Seung Shin Yang, Hong Sun Ryou, Myong O Yoon, Youn Tae Jeong. 2008. An experimental study on the effect of ventilation velocity on burning rate in tunnel fires - heptane pool fire case. Building and Environment, 43, 1225-1231.

[11] Kuang-Chung Tsai, Yee-Ping Lee, Shin-Ku Lee. 2011. Critical ventilation velocity for tunnel fires occurring near tunnel exits. Fire safety Journal, 46, 556-557.

[12] Jae Seong Roh, Hong Sun Ryou, Dong Hyeon Kim, Woo Sung Jung, Yong Jun Jang. 2007. Critical velocity and burning rate in pool fire during longitudinal ventilation. Tunneling and Underground Space Technology, 22, 262-271.

[13] Ciro Caliendo, Paolo Ciambelli, Maria Luisa, De Guglielmo, Maria Grazia Meo, Paola Russo. 2012 Numerical simulation of different $\mathrm{HGV}$ fire scenarios in curved bi-directional road tunnels and safety evaluation. Tunneling and Underground Space Technology, 31, 3350. 